\title{
Determination of the Critical Buckling Load of Shear Deformable Unified Beam
}

\author{
M. E. ONYIA ${ }^{1}$ and E. O. ROWLAND-LATO ${ }^{2}$ \\ ${ }^{1,2}$ Department of Civil Engineering, University of Nigeria, Nsukka. Nigeria. \\ 1michael.onyia@unn.edu.ng
}

\begin{abstract}
This paper presents a finite element formulation for the determination of the critical buckling load of unified beam element that is free from shear locking using the energy method. The formulated element is used for the determination of the critical buckling load of beams with different boundary conditions. The developed formulae for the determination of critical buckling load are based on the effect of shear deformation. Numerical results for the critical buckling load of the classical Euler-Bernoulli beam and Timoshenko beam are presented and compared with the exact solutions.

It is shown that the proposed technique provides a unified approach for the stability analysis of beams with any end conditions. It is concluded that for design purposes, shear deformation may be safely ignored for beam span-to-depth (1/d) ratio greater than 10, while for $1 / d$ ratio of 5 and less, shear deformation effect is significant and should be accounted for.
\end{abstract}

Keywords: beam, column, buckling, stability, stiffness, shear locking.

\subsection{Introduction}

Beams as structural members are of interest in many engineering applications. Some of the applications include structural frames, pile foundations, grillages, and spread footings supported on groups of piles. The EulerBernoulli theory considers the displacement of beams without shear effects. This approach gives appropriate and acceptable response in slender beams, in which shear effect is insignificant. The Timoshenko beam theory, on the other hand, is known to be superior to the Euler-Bernoulli beam model in predicting the transient response of beams, [1]. The Timoshenko beam theory employs a more accurate representation of beam flexure which allows for the inclusion of shear strains and is therefore more suited for thick beam analysis. Present conventional and most shear deformable beam finite elements may give acceptable results in solutions of particular problems but require substantial mesh refinement to achieve convergent solutions in others and as such fail in generality.

It has been observed that the use of linear shape functions to represent transverse deflection, w, and crosssectional rotation, $\theta$, in a Timoshenko beam leads to an overly stiff element. The net displacement will therefore be much less than that observed in the actual structure. Such behaviour is known as shear locking, ([2], [3], [5]). The shear locking phenomenon results when the stiffness of the structure is significantly over-predicted (i.e. displacement is under-predicted) due to the inconsistency of the assumed interpolation function.

The proposed unified beam element accommodates the quadratic variation of the transverse shear strain. This paper proposes a new method for determining the critical buckling load of beams with inclusion of shear deformation..

\subsection{Finite Element Formulation}

Consider a two-node, straight, prismatic beam element made of a homogenous linear elastic material with modulus of elasticity, E, moment of inertia, I, and cross-sectional area, A. (Fig. 1).

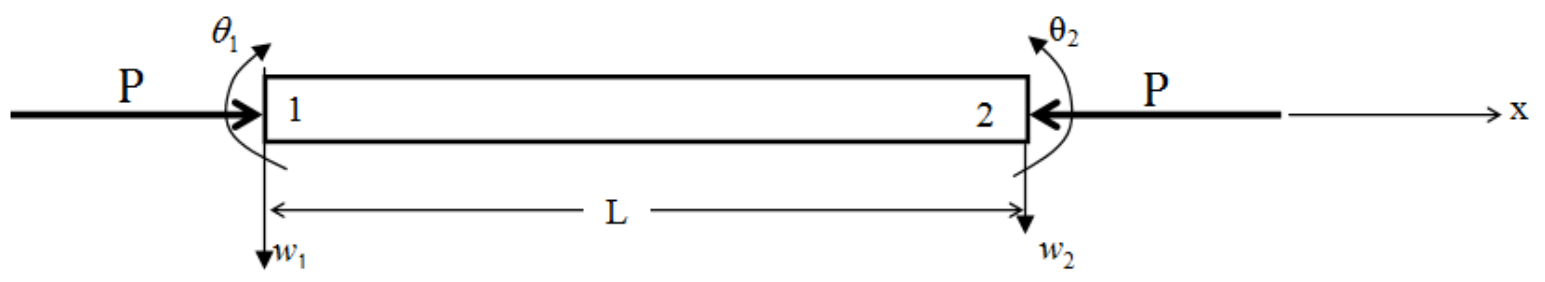

Fig. 1 - Beam element

\subsection{Interpolation Functions}

In formulating the interpolation functions, the beam deflection $w$ is divided into two components; that due to the flexure, $\mathrm{w}_{\mathrm{b}}$, and that due to transverse shear, $\mathrm{w}_{\mathrm{s}}$. The angle of rotation of the cross-section $\theta$ is divided into its constitutive parts; the angle of cross-section rotation due to bending, $\theta_{b}$ and the cross-section slope due to shear,

$\theta_{s}$ (see Figure.2). 


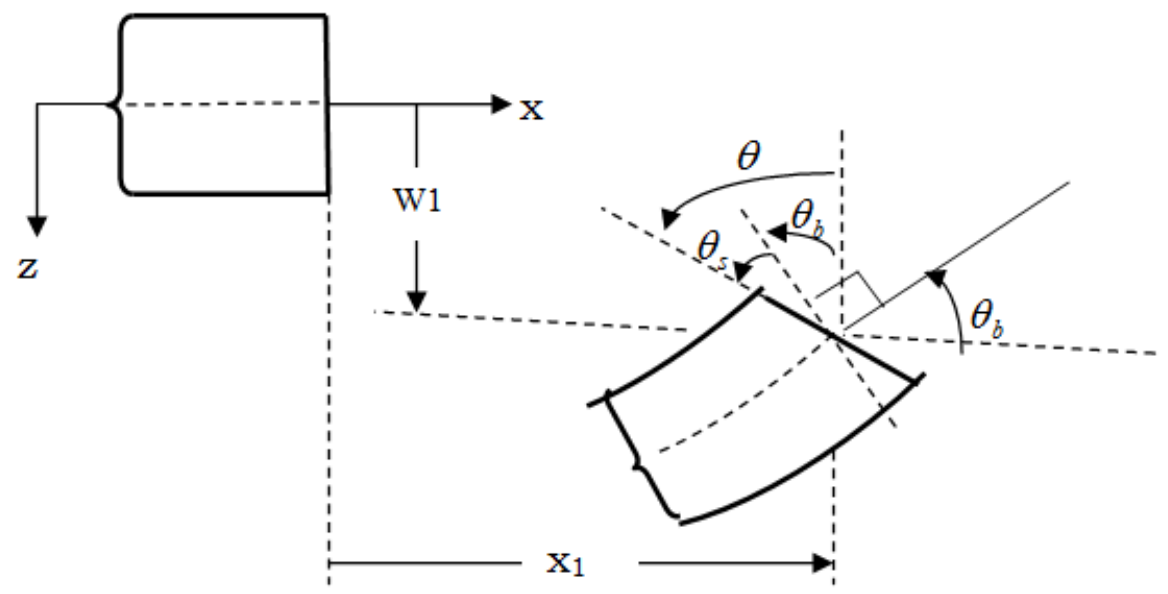

Fig. 2 - Kinematics of a beam undergoing both bending and shear rotations

Using Hermite cubic polynomial to approximate the flexural deformation, $w_{b}(x):[\mathbf{4 , 6}]$

$w_{b}(x)=a_{1}+a_{2} x+a_{3} x^{2}+a_{4} x^{3}$

$\theta_{b}(x)=\frac{d w_{b}(x)}{d x}=a_{2}+2 a_{3} x+3 a_{4} x^{2}$

The coefficients $a_{1}, a_{2}, a_{3}$ and $a_{4}$ are determined from the boundary conditions of the beam element:

$w_{b}(x=0)=w_{b 1}=a_{1}$

$w_{b}(x=l)=w_{b 2}=a_{1}+a_{2} \mathrm{~L}+a_{3} L^{2}+a_{4} L^{3}$

$\theta_{b}(x=0)=\theta_{b 1}=a_{2}$

$\theta_{b}(x=l)=\theta_{b 2}=a_{2}+2 a_{3} L+3 a_{4} L^{2}$

Thus, the generalized nodal displacements for the Bernoulli beam are defined by $w_{b}$

$w_{b}(x)=\sum_{i=1}^{4} \varphi_{i}(x)\left\{u_{i}\right\}$

where $\left\{u_{i}\right\}$ denotes the column displacement vectors $\left\{w_{b 1}, \theta_{b 1}, w_{b 2}, \theta_{b 2}\right\}^{T}$

and the $\varphi_{i}$ 's are given as

$$
\varphi_{1}=\frac{L^{3}-3 L x^{2}+2 x^{3}}{L^{3}}, \varphi_{2}=\frac{x L^{3}-2 L^{2} x^{2}+L x^{3}}{L^{3}}, \varphi_{3}=\frac{3 L x^{2}-2 x^{3}}{L^{3}}, \varphi_{4}=\frac{x^{3}-L x^{2}}{L^{2}}
$$

Using a quadratic polynomial to approximate the shear deformation, $w_{s}(x):$ [7]

$$
\begin{aligned}
& w_{s}(x)=1+b_{1}+b_{2} x+b_{3} x^{2} \\
& \theta_{s}(x)=\frac{d w_{s}(x)}{d x}=1+b_{2}+2 b_{3} x
\end{aligned}
$$

The coefficients $b_{1}, b_{2}$ and $b_{3}$ are determined from the boundary conditions:

$w_{s}(x=0)=w_{s 1}=1+b_{1}$

$w_{s}(x=l)=w_{s 2}=1+b_{1}+b_{2} \mathrm{~L}+b_{3} L^{2}$

$\theta_{s}(x=0)=\theta_{s 1}=1+b_{2}$

$\theta_{s}(x=l)=\theta_{s 2}=1+b_{2}+2 b_{3} L$ 
The generalized nodal displacements for the shear beam are defined as $w_{s}$ and $\theta_{s}$

$$
w_{s}(x)=\sum_{i=1}^{4} \eta_{i}(x)\left\{u_{i}\right\}
$$

where $\left\{u_{i}\right\}$ denotes the column displacement vector $\left\{w_{s 1}, \theta_{s 1}, w_{s 2}, \theta_{s 2}\right\}^{T}$

and the $\eta_{i}$ 's are given as

$$
\eta_{1}=1-\frac{x}{L}, \eta_{2}=\frac{L}{2}\left(\frac{x}{L}-\left(\frac{x}{L}\right)^{2}\right), \eta_{3}=\frac{x}{L} \text { and } \eta_{4}=-\frac{L}{2}\left(\frac{x}{L}-\left(\frac{x}{L}\right)^{2}\right)
$$

\subsection{Bending-Shear Interaction Factor}

To ensure continuous interaction between the bending and shear components as a function and to avoid the use of partial derivatives, an expression for the total cross sectional rotation $\theta$ is proposed as: [8]

$\theta(x)=\beta \theta_{b}(x)+(1-\beta) \theta_{s}(x)$

where $\theta(x)$ is the total cross-sectional rotation of the beam

$\theta_{b}(x)$ is the cross-sectional rotation of the Euler-Bernoulli beam

$\theta_{S}(x)$ is the cross-sectional rotation of the shear beam

$\beta$ is the bending-shear interaction factor and is expressed as the ratio of bending strain energy to total strain energy of a simply-supported beam under load.

That is:

$\beta=\frac{q_{b}}{q}=\frac{U_{b}}{U_{b}+U_{s}}=\frac{1}{1+\Phi}$

where $\Phi=\frac{U_{s}}{U_{b}}$

$U_{b}=$ bending strain energy

$U_{s}=$ shear strain energy

The integral expression for bending strain energy is given by the familiar expression:

$U_{b}=\int_{0}^{L} \frac{(M(x))^{2}}{2 E I} d x$

where $\mathrm{E}$ is the elastic modulus of the beam material.

$\mathrm{I}=$ moment of inertia of the beam section.

Consider a simply supported beam with a point load $\mathrm{P}$ at midspan.

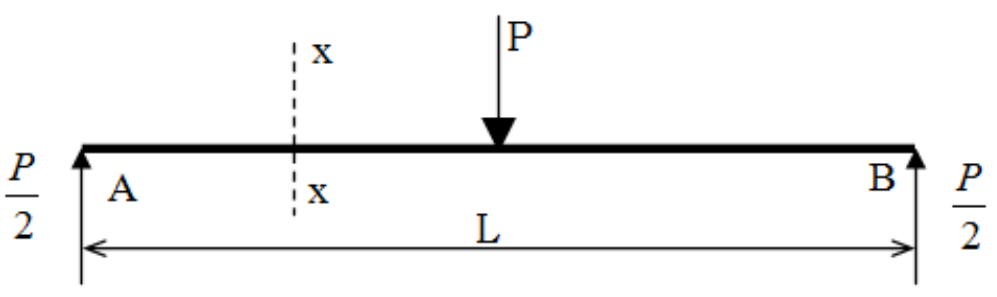

Fig. 3- A simply supported beam under a point load $\mathrm{P}$ at the center

The bending moment at a section, distance $\mathrm{x}$ from a support, is given by:

$M(x)=\frac{P x}{2}, \mathrm{x}<\mathrm{L} / 2 \quad$ and $M(x)=\frac{P x}{2}-P\left(x-\frac{L}{2}\right), \mathrm{x}>\mathrm{L} / 2$

Since the maximum bending moment occurs at midspan $(x=L / 2)$,

$M(x)=\frac{P x}{2}$ 
Substituting for $M(x)$ in Equation (11) and performing integration gives

$$
\therefore U_{b}=\frac{P^{2} L^{3}}{96 E I}
$$

The shear force at any section, distance $\mathrm{x}$ from a support, is:

$Q(x)=\frac{P}{2}$

The integral expressions for shear strain energy is given by the familiar expression

$U_{s}=\int_{0}^{L} \frac{(Q(x))^{2}}{2 k A G} d x$

Substituting for $Q(x)$ in Equation (15) gives the shear strain energy as:

$U_{s}=\frac{P^{2} L}{8 k A G}$

$\therefore \Phi=\frac{U_{s}}{U_{b}}=\frac{12 E I}{L^{2} k A G}$

where $\mathrm{E}=$ Young's modulus

$\mathrm{G}=$ shear modulus

$\mathrm{A}=$ cross-sectional area

$\mathrm{k}=$ shear coefficient depending on the shape of cross-section.

Edem [8] proposed that the bending-shear interaction factor, $\beta$, be based on the value of $\Phi$ for midspan point load, i.e. Equation (17).

\subsection{Beam Element Stiffness Matrix}

The bending strain energy of the Euler-Bernoulli beam is given Equation (11):

$U_{b}=\int_{0}^{L} \frac{(M(x))^{2}}{2 E I} d x$

where $M(x)$ is the bending moment.

But Curvature is $\dot{\theta}_{x}=\frac{M(x)}{E I}$

Thus $U_{b}=\frac{1}{2} \int_{0}^{L} E I\left(\dot{\theta}_{x}\right)^{2} d x$

where $\theta(x)$ is the slope.

Using the expression for the total cross-sectional rotation (Equation 9), the total energy in the unified beam element under a distributed normal load $\mathrm{q}$ is expressed as:

$U\left(\theta_{b}, \theta_{s}\right)=\frac{E l}{2} \int_{0}^{L}\left[\beta \dot{\theta}_{b}^{2}+(1-\beta) \dot{\theta}_{s}^{2}\right] d x$

From Equations (3) and (7):

$\dot{\theta}_{b}(x)=\sum_{i=1}^{4} \ddot{\varphi}_{i}(x) u_{i}$ for the flexural beam

$\dot{\theta}_{s}(x)=\sum_{i=1}^{4} \ddot{\eta}_{i}^{\prime}(x) u_{i} \quad$ for the shear beam

From Castigliano's first theorem, the stiffness coefficient $\mathrm{K}_{\mathrm{ij}}$ is given by 


$$
\begin{aligned}
& K_{i j}=\frac{\partial}{\partial u_{i}} \frac{\partial}{\partial u_{j}} U_{p}(\theta) \\
& K_{i j}=\frac{\partial}{\dot{u}_{i}} \frac{\partial}{\dot{u}_{j}} \frac{1}{2} \int_{x=0}^{L} \beta E I\left(\sum_{k=1}^{4} \ddot{\varphi}_{i}(x) u_{i}\right)^{2} d x+\frac{\partial}{\dot{u}_{i}} \frac{\partial}{\dot{u}_{j}} \frac{1}{2} \int_{x=0}^{L}(1-\beta) E I\left(\sum_{k=1}^{4} \ddot{\eta}_{i}(x) u_{i}\right)^{2} d x \\
& =\int_{x=0}^{L} \beta E I \ddot{\varphi}_{i}(x) \ddot{\varphi}_{j}(x) d \bar{x}+\int_{x=0}^{L}(1-\beta) E I \ddot{\eta}_{i}(x) \ddot{\eta}_{j}(x) d \bar{x}
\end{aligned}
$$

where $\ddot{\varphi}_{i}=\frac{d^{2} \varphi_{i}}{d x^{2}}$ and $\ddot{\eta}_{i}=\frac{d^{2} \eta_{i}}{d x^{2}}$

The assembled unified beam element stiffness matrix is $\mathrm{K}$ is

$K=\frac{\beta E l}{L^{3}}\left[\begin{array}{llll}12 & 6 L & -12 & 6 L \\ 6 L & (4+\Phi) L^{2} & -6 L & (2-\Phi) L^{2} \\ -12 & -6 L & 12 & -6 L \\ 6 L & (2-\Phi) L^{2} & -6 L & (4+\Phi) L^{2}\end{array}\right]$

$\Phi=\frac{1-\beta}{\beta}$

\subsection{Beam Element Stability Matrix}

The stability matrix is formulated using the kinetic energy principle.

Consider a long compression member shown in Figure 4

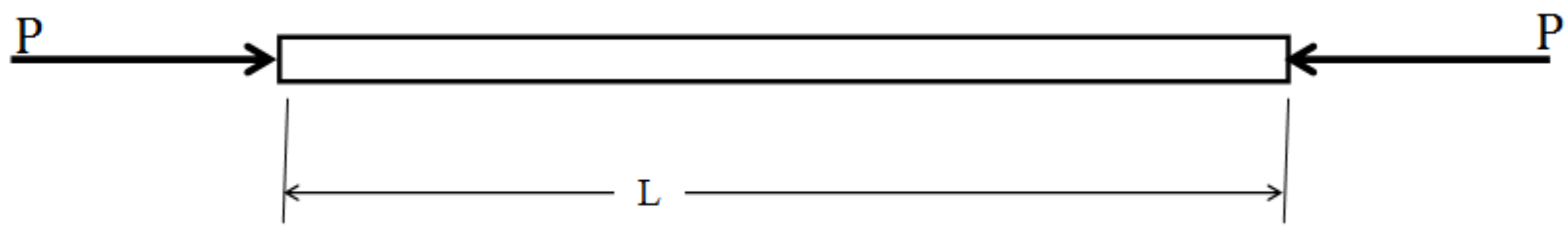

Fig. 4 - Beam under compression

If an axial load $\mathrm{P}$ is applied and increased slowly, it will ultimately reach a value $\mathrm{P}_{\mathrm{cr}}$ that will cause buckling of the beam or column. $\mathrm{P}_{\mathrm{cr}}$ is called the critical buckling load of the beam or column.

The total kinetic energy for the rotation of the cross-section due to bending is given by

$U_{K}=\frac{1}{2} \sum_{i} P_{i} \theta_{i}^{2}$

Following the finite element method philosophy, the element displacement field is interpolated for flexure and shear rotation by shape functions, Equations (3) and (7):

$$
\begin{aligned}
& w_{b}(x)=\sum_{i=1}^{4} \varphi_{i}(x)\left\{u_{i}\right\} \\
& w_{s}(x)=\sum_{i=1}^{4} \eta_{i}(x)\left\{u_{i}\right\}
\end{aligned}
$$

The rotation of the cross-section is given by Equation (9):

$\theta(x)=\beta \theta_{b}(x)+(1-\beta) \theta_{s}(x)$

Or $\theta(x)=\beta \sum_{\mathrm{i}=1}^{4} \dot{\varphi}_{\mathrm{i}}(x) \mathrm{u}_{\mathrm{i}}+(1-\beta) \sum_{\mathrm{i}=1}^{4} \dot{\eta}_{\mathrm{i}}(\mathrm{x}) \mathrm{u}_{\mathrm{i}}$

where the $\dot{\varphi}_{i}=\frac{d \varphi_{i}}{d x}$ and $\dot{\eta}_{i}=\frac{d \eta_{i}}{d x}$ 
The stability coefficient is given by

$$
\begin{aligned}
& K_{G_{i j}}=\frac{\partial}{\partial u_{i}} \frac{\partial}{\partial u_{j}} U_{K}(\theta) \\
& K_{G_{i j}}=\frac{\partial}{\dot{u}_{i}} \frac{\partial}{\dot{u}_{j}} \frac{1}{2} \int_{x=0}^{L} P\left(\beta \sum_{k=1}^{4} \dot{\varphi}_{i}(x) u_{i}\right)^{2} d x+\frac{\partial}{\dot{u}_{i}} \frac{\partial}{\dot{u}_{j}} \frac{1}{2} \int_{x=0}^{L} P\left((1-\beta) \sum_{k=1}^{4} \dot{\eta}_{i}(x) u_{i}\right)^{2} d x \\
& =\beta \int_{\mathrm{x}=0}^{\mathrm{L}} \mathrm{P} \dot{\varphi}_{\mathrm{i}}(\mathrm{x}) \dot{\varphi}_{\mathrm{j}}(\mathrm{x}) \mathrm{d} \mathrm{x}+(1-\beta) \int_{\mathrm{x}=0}^{\mathrm{L}} \mathrm{P} \dot{\eta}_{\mathrm{i}}(\mathrm{x}) \dot{\eta}_{\mathrm{j}}(\mathrm{x}) \mathrm{dx}
\end{aligned}
$$

The assembled unified beam element stability matrix is

$$
K_{g}=\frac{\beta P}{30 L}\left[\begin{array}{lccl}
(36+30 \Phi) & 3 L & -(36+30 \Phi) & 3 L \\
3 L & (4+5 / 2 \Phi) l^{2} & -3 \mathrm{~L} & -(1+5 / 2 \Phi) L^{2} \\
-(36+30 \Phi) & -3 \mathrm{~L} & (36+30 \Phi) & -3 L \\
3 L & -(1+5 / 2 \Phi) L^{2} & -3 L & (4+5 / 2 \Phi) L^{2}
\end{array}\right]
$$

where $\Phi=\frac{1-\beta}{\beta}$

\subsection{Governing Equilibrium Equations}

Consider an element of a beam-column in the deformed position with the forces acting as shown in Fig. 5:

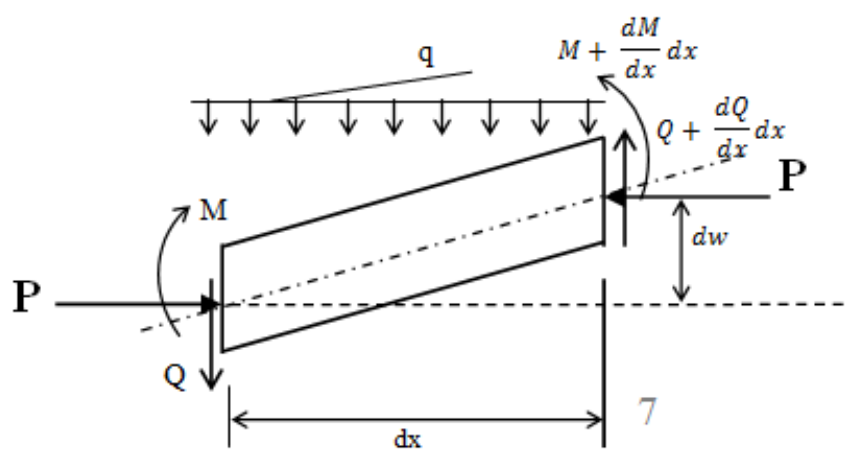

Fig. 4 - Axially-loaded propped cantilever beam

Considering vertical equilibrium:

$$
\frac{\mathrm{dQ}}{\mathrm{dx}}=\mathrm{q}
$$

Taking moments and ignoring second-order terms,

$\frac{\mathrm{dM}}{\mathrm{dx}}+\mathrm{Q}+\mathrm{P} \frac{\mathrm{dw}}{\mathrm{dx}}=0$

Differentiating with respect to $\mathrm{X}$ :

$\frac{\mathrm{d}^{2} \mathrm{M}}{\mathrm{dx}^{2}}+\frac{\mathrm{dQ}}{\mathrm{dx}}+\mathrm{P} \frac{\mathrm{d}^{2} \mathrm{w}}{\mathrm{dx}^{2}}=0$

But $\mathrm{M}=\frac{\mathrm{EId}^{2} \mathrm{w}}{\mathrm{dx}^{2}}$ and $\frac{\mathrm{dQ}}{\mathrm{dx}}=\mathrm{q}$

$\therefore \mathrm{EI} \frac{\mathrm{d}^{4} \mathrm{w}}{\mathrm{dx}^{4}}+\mathrm{P} \frac{\mathrm{d}^{2} \mathrm{w}}{\mathrm{dx}^{2}}=-\mathrm{q}$

Equation (31) is the beam-column differential equation.

The strain energy due to bending is:

$U(\theta)=\int_{0}^{L} \frac{M^{2}}{2 E I} d x$ 
where $\mathrm{M}$ is the bending moment.

But $\mathrm{M}=\frac{\mathrm{EId}^{2} \mathrm{w}}{\mathrm{dx}^{2}}$

$U(\theta)=\int_{0}^{L} \frac{E I}{2}\left(\frac{d^{2} w}{d x^{2}}\right)^{2} d x$

But $\frac{\mathrm{dw}}{\mathrm{dx}}=\theta$

$\therefore U(\theta)=\int_{0}^{L} \frac{E I}{2}\left(\frac{d \theta}{d x}\right)^{2} d x$

The force $\mathrm{P}$ will move through a distance given by

$\delta=\int_{0}^{L} \frac{1}{2}\left(\frac{d w}{d x}\right)^{2} d x$

Thus, the total potential energy is given by

$$
\begin{aligned}
& U(\theta, P, q)=\int_{0}^{L} \frac{E I}{2}\left(\frac{d^{2} w}{d x^{2}}\right)^{2} d x-\frac{P}{2} \int_{0}^{L}\left(\frac{d w}{d x}\right)^{2} d x-\int_{0}^{L} q w \\
& \text { i.e. } U(\theta, P, q)=\frac{E I}{2} \int_{0}^{L}\left(\frac{d^{2} \theta}{d x^{2}}\right)^{2} d x-\frac{P}{2} \int_{0}^{L}\left(\frac{d \theta}{d x}\right)^{2} d x-\int_{0}^{L} q w
\end{aligned}
$$

For equilibrium, the total potential energy is minimum:

i.e. $\frac{d}{d x} U(\theta, P, q)=0$

or $\frac{E I}{2} \int_{0}^{L}\left(\frac{d^{2} \theta}{d x^{2}}\right)^{2} d x-\frac{P}{2} \int_{0}^{L}\left(\frac{d \theta}{d x}\right)^{2} d x-\int_{0}^{L} q w=0$

For stability analysis and determination of the magnitude of the static compressive axial load that will cause the beam to buckle, the lateral load $\mathrm{q}=0$.

Thus, the critical buckling load $\mathrm{P}_{\mathrm{cr}}$ that satisfies Equation (33) is:

$\frac{E I}{2} \int_{0}^{L}\left(\frac{d^{2} \theta}{d x^{2}}\right)^{2} d x-\frac{P_{c r}}{2} \int_{0}^{L}\left(\frac{d \theta}{d x}\right)^{2} d x=0$

But from Equations (22) and (28):

$K_{i j}=\frac{\partial}{\partial u_{i}} \frac{\partial}{\partial u_{j}} U_{p}(\theta)$

and $K_{G_{i j}}=\frac{\partial}{\partial u_{i}} \frac{\partial}{\partial u_{j}} U_{K}(\theta)$

Substituting into Equation (34) and taking $\mathrm{u}=\mathrm{w}$ :

$\left[K-P_{c r} K_{G}\right] w=0$

where $\mathrm{K}$ = structure stiffness matrix given by Equation (21) 


$$
\begin{aligned}
K_{G} & =\text { stability matrix given by Equation (26) } \\
P_{c r} & =\text { critical buckling load } \\
\mathrm{W} & =\text { vector of structure nodal displacement }
\end{aligned}
$$

Equation (35) is an eigenvalue problem which gives nontrivial solution when $\mathrm{P}_{\text {cr }}$ satisfies the equation:

$\operatorname{det}\left(K-P_{c r} K_{G}\right)=0$

The lowest positive eigenvalue of this equation is the magnitude of the buckling load and the corresponding eigenvector is the deformed shape of the buckled beam.

Substituting for $[\mathrm{K}]$ and $\left[\mathrm{K}_{\mathrm{G}}\right]$ in Equation (36) gives:

$$
\operatorname{det}\left[\begin{array}{c}
\frac{\beta E I}{L^{3}}\left[\begin{array}{cccc}
12 & 6 L & -12 & 6 L \\
6 L & (4+\Phi) L^{2} & -6 L & (2-\Phi) L^{2} \\
-12 & -6 L & 12 & -6 L \\
6 L & (2-\Phi) L^{2} & -6 L & (4+\Phi) L^{2}
\end{array}\right] \\
-\frac{\beta P}{30 L}\left[\begin{array}{llcc}
(36+30 \Phi) & 3 L & -(36+30 \Phi) & 3 L \\
3 L & (4+5 / 2 \Phi) L^{2} & -3 L & -(1+5 / 2 \Phi) L^{2} \\
-(36+30 \Phi) & -3 L & (36+30 \Phi) & -3 L \\
3 L & -(1+5 / 2 \Phi) L^{2} & -3 L & (4+5 / 2 \Phi) L^{2}
\end{array}\right]
\end{array}\right]=0
$$

\subsection{Presentation And Discussion Of Results}

Consider the propped cantilever beam loaded axially with $\mathrm{P}$ as shown in Fig. 5:

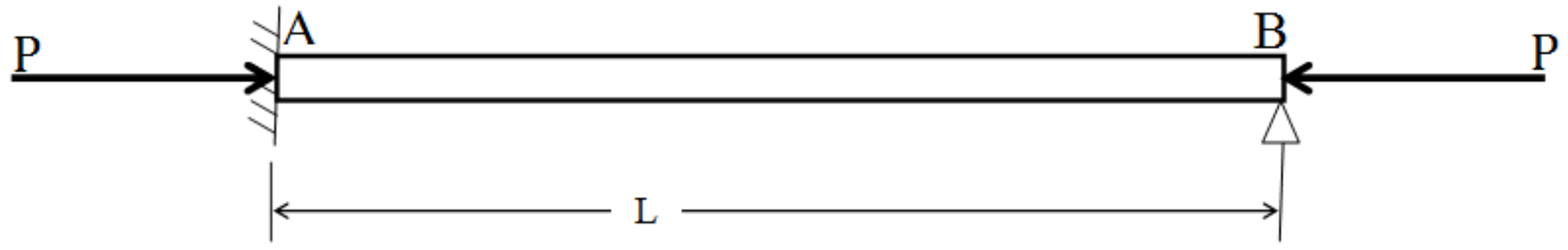

Fig. 5 - Axially-loaded propped cantilever beam

A 2-element finite element idealization of the beam is shown in Fig. 6

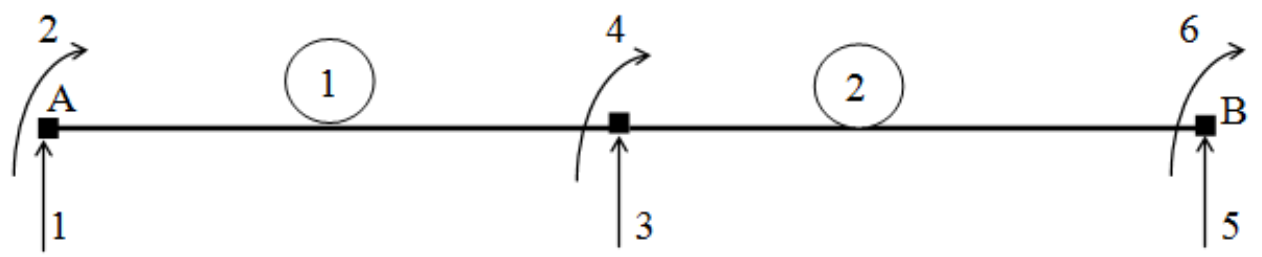

Fig. 6 - Finite element idealization of beam structure

The nodal displacements are numbered as shown.

The boundary conditions of the propped cantilever are

$\mathrm{W}_{\mathrm{A}}=\mathrm{W}_{\mathrm{B}}=\theta_{\mathrm{A}}=0$

Expanding equation (37) for the two elements and implementing the boundary conditions (noting that $\mathrm{L}=1 / 2$ for each element) leads to Equation (38): 
$\left[\begin{array}{ccc}{\left[\begin{array}{ccc}24 & 0 & 3 L \\ 0 & (4+\Phi) \frac{L^{2}}{2} & (2-\Phi) \frac{L^{2}}{2} \\ 3 L & (2-\Phi) \frac{L^{2}}{2} & (4+\Phi) \frac{L^{2}}{2}\end{array}\right]} \\ -\frac{\lambda}{120}\left[\begin{array}{ccc}(72+60 \Phi) & 0 & \frac{3}{2} L \\ 0 & (4+5 / 2 \Phi) \frac{L^{2}}{2} & -(1+5 / 2 \Phi) \frac{L^{2}}{2} \\ \frac{3}{2} L & -(1+5 / 2 \Phi) \frac{L^{2}}{2} & (4+5 / 2 \Phi) \frac{L^{2}}{2}\end{array}\right]\end{array}\right]=0$

where $\lambda=\frac{\mathrm{PL}^{2}}{\mathrm{EI}}$

Solving Equation (38) gives:

$\lambda=20.089+14.7285 \Phi+2.1928 \Phi^{2}$

Thus the critical buckling load is

$\mathrm{P}_{\mathrm{cr}}=\frac{20.7089 \mathrm{EI}}{\mathrm{L}^{2}}\left(1+0.7112 \Phi+0.1059 \Phi^{2}\right)$

Using the relationship given by Equation (17) for $\Phi$ :

$\Phi=\frac{12 E I}{L^{2} k A G}$

The following parameters are assumed for the beam section, [11]:

(i) Shear correction factor, $k=5 / 6$

(ii) Poisson's ratio, $v=0.25$

(iii) $\mathrm{L} / \mathrm{d}=100$

$\mathrm{G}=\frac{\mathrm{E}}{2(1+\mathrm{v})}=\frac{\mathrm{E}}{2(1+0.25)}=\frac{\mathrm{E}}{2.5}$

$\Phi=\frac{12 E I}{L^{2} k A G}$

$=\frac{12 \mathrm{E}}{\mathrm{L}^{2}}\left(\frac{\mathrm{bd}^{3}}{12}\right)\left(\frac{1}{\mathrm{bd}}\right)\left(\frac{2.5}{\mathrm{E}}\right)\left(\frac{6}{5}\right)$

i.e. $\Phi=3\left(\frac{d}{\mathrm{~L}}\right)^{2}$

Substituting for $\Phi$ in Equation (39) and $\mathrm{L} / \mathrm{d}=100$, the critical buckling load of the beam is:

$\mathrm{P}_{\mathrm{cr}}=\frac{20.7132 \mathrm{EI}}{\mathrm{L}^{2}}$

In general, the Euler critical buckling load for any support condition is given by: [9, 10]

$\mathrm{P}_{\mathrm{cr}}=\frac{\pi^{2} \mathrm{EI}}{(\mathrm{KL})^{2}}$

where $\mathrm{K}=$ effective length factor

$\therefore \mathrm{K}=\sqrt{\frac{\pi^{2} \mathrm{EI}}{\mathrm{L}^{2} \mathrm{P}_{\mathrm{cr}}}}$

Substituting $\mathrm{P}_{\mathrm{cr}}=\frac{20.7089 \mathrm{EI}}{\mathrm{L}^{2}}(1+0.7112 \Phi)$ as derived for the propped cantilever beam (neglecting higher degree of $\Phi)$, then

$\therefore \mathrm{K}=\sqrt{\frac{\pi^{2}}{20.7089(1+0.7112 \Phi)}}$ 
i.e. $K=\frac{1}{\sqrt{2.10+1.49 \Phi}}$

Similar finite element analysis using a 2-element mesh is performed for other support conditions of the beam and the results are presented in Table 1:

Table 1 - Derived Formulae for the Critical Buckling Load and Effective Length of Beams

\begin{tabular}{|l|c|c|}
\hline Support Condition & $\begin{array}{c}\text { Critical Buckling Load, } \mathbf{P}_{\mathbf{c r}} \\
\left(\mathbf{x} \frac{\mathbf{E I}}{\mathbf{L}^{2}}\right)\end{array}$ & Effective Length Factor, K \\
\hline Pinned-Pinned & $9.94(1+0.92 \Phi)$ & $\frac{1}{\sqrt{1.01+0.92 \Phi}}$ \\
\hline Clamped-Free & $2.47(1+2.52 \Phi)$ & $\frac{1}{\sqrt{0.25+0.63 \Phi}}$ \\
\hline Clamped-Pinned & $20.71(1+0.72 \Phi)$ & $\frac{1}{\sqrt{2.10+1.49 \Phi}}$ \\
\hline Clamped-Clamped & $40.004(1+0.37 \Phi)$ & $\frac{1}{\sqrt{4.05+1.49 \Phi}}$ \\
\hline
\end{tabular}

Legend:

$\mathrm{E}=$ Modulus of elasticity $\left(\mathrm{N} / \mathrm{m}^{2}\right)$

$\mathrm{L}=$ Length of beam $(\mathrm{m})$

$\Phi=3(\mathrm{~d} / \mathrm{L})^{2}$

The effect of span-to-depth (1/d) ratio of beam on the critical buckling load for different support conditions is presented in Table 2 .

The parameters assumed for the beam section are, [11]:

(i) Shear correction factor, $\mathrm{k}=5 / 6$

(ii) Poisson's ratio, $\mathrm{v}=0.25$

Table 2 - Relationship Between Span/depth (L/d) Ratio and $\left(P_{c r} / P_{c r E}\right)$ Ratio

\begin{tabular}{|c|c|c|c|c|}
\hline (L/d) & Pinned-Pinned & Clamped-Free & Clamped-Pinned & Clamped-Clamped \\
\hline 100 & 1.01 & 1.00 & 1.00 & 1.01 \\
\hline 20 & 1.01 & 1.02 & 1.00 & 1.02 \\
\hline 10 & 1.03 & 1.08 & 1.02 & 1.02 \\
\hline 5 & 1.13 & 1.35 & 1.09 & 1.06 \\
\hline 4 & 1.21 & 1.60 & 1.14 & 1.08 \\
\hline 2 & 2.11 & 4.86 & 1.59 & 1.29 \\
\hline 1 & 10.39 & 40.07 & 4.11 & 2.14 \\
\hline
\end{tabular}

Legend:

$P_{c r}$ - critical buckling load of Unified beam

$P_{c r E}$ - critical buckling load of Timoshenko beam

A comparison of solutions for the critical buckling load of beams for different support conditions using analytical, Timoshenko and Unified beam models is presented in Table 3.

The following parameters are assumed for the beam section, [6]:

(i) Shear correction factor, $\mathrm{k}=5 / 6$

(ii) Poisson's ratio, $v=1 / 3$

(iii) Modulus of elasticity, $\mathrm{E}=10^{7} \mathrm{~N} / \mathrm{mm}^{2}$ 
The beam was discretised into five finite elements in each case.

Table 3 - Comparison of Critical Buckling Load of Beams Using Different Models

\begin{tabular}{|l|c|c|c|c|c|c|}
\hline \multirow{2}{*}{ L/d } & \multicolumn{2}{|c|}{ Simply- Supported Ends } & \multicolumn{3}{c|}{ Fixed Ends } \\
\cline { 2 - 7 } & Analytical & TBT & UBE & Analytical & TBT & UBE \\
\hline 10 & 8013.80 & 8013.86 & $\mathbf{8 0 1 4 . 9 7}$ & 29766 & 29877 & $\mathbf{2 9 8 8 0}$ \\
\hline 100 & 8.223 & 8.231 & $\mathbf{8 . 2 2 4}$ & 32.864 & 32.999 & $\mathbf{3 3 . 6 6 6}$ \\
\hline 1000 & 0.0082 & 0.0082 & $\mathbf{0 . 0 0 8 2}$ & 0.0329 & 0.0330 & $\mathbf{0 . 0 3 3 8}$ \\
\hline
\end{tabular}

Legend: UBE - Unified Beam Element, TBT - Timoshenko Beam Element

The results in Table 1 demonstrate the advantage of the shear locking-free unified beam elements. The results show that it requires just a 2-element mesh to produce excellent results, in contrast to the 16-element mesh used by Reddy [11] for the same problem. The unified beam element thus models shear deformation extremely closely, [12]. The results also show that the shear deformation parameter $\Phi$ influences the critical buckling load. As the beam changes from stocky to slender, the shear deformation parameter reduces from 1 to 0 , and the critical buckling analysis reduces to classical solution. This is also applicable to the effective length factor.

The results in Table 2 show that shear deformation contributes less than $5 \%$ to the critical buckling load for $\mathrm{L} / \mathrm{d}$ ratio greater than 10 . Also, the critical buckling load increases as the $\mathrm{L} / \mathrm{d}$ ratio decreases

The results in Table 3 demonstrate the accuracy of the unified beam element model for both deep and slender beams in comparison with the analytical and Timoshenko beam models.

\subsection{Conclusion}

In this paper, a unified beam element model of the Euler-Bernoulli and Timoshenko beam theories is developed. Bending stiffness and stability coefficients of the unified beam element are derived by employing a bendingshear interaction factor. Explicit formulae for the critical buckling loads and effective lengths of Timoshenko beams based on the proposed unified element have been developed for different support conditions.

The numerical examples presented demonstrate the validity and accuracy of the proposed unified beam element model in the evaluation of the critical buckling load of beams. The results suggest that for design purposes, shear deformation may be safely ignored for beam span-to-depth (1/d) ratio greater than 10 , while for $1 / \mathrm{d}$ ratio of 5 and less, shear deformation effect is significant and should be accounted for.

\section{Refrences}

[1] Henshell, R.R.D. and Warburton, G. B. (1972): "A Timoshenko Beam Element”, Journal of Sound and Vibration, Vol. 22, pp. 475487.

[2] Friedman Z. and Kosmatka, J. B. (1993): “An Improved Two-Node Timoshenko Beam Finite Element”, Computer and. Structures, Vol. 47, pp. 473-481

[3] Reddy, J.N. (1997):“On Locking-Free Shear-Deformable Beam Finite Elements", Computational Methods of Applied Mechanics in Engineering, Vol.149, pp. 113-132

[4] Kosmatka, J. B.(1995), "An Improved Two-Node Finite Element for Stability and Natural Frequencies of Axial-Loaded Timoshenko Beams", Computers and Structures, Vol. 57, Issue 1, pp. 141-149.

[5] Reddy, J. N., Wang, C. M. and Lam, K. Y. (1997): "Unified Finite Elements Based on the Classical and Shear Deformation Theories of Beams and Axisymmetric Circular Plates", International Journal of Numerical Methods in Engineering, Vol. 13, pp.495-510.

[6] Abbas, M. and Mohammad, K. (2013): "Finite Element Formulation for Stability and Free Vibration Analysis of Timoshenko Beam", Advances in Acoustics and Vibration, Vol. 2013, Article ID 841215, Hindawi Publishing Corporation.

[7] Rakowski, J. (1991): “A Critical Analysis of Quadratic Beam Finite Elements”, International Journal. of Numerical methods in Engineering, Vol. 31, pp. 949-966.

[8] Edem, I. B. (2006):“"The Exact Two-Node Timoshenko Beam Finite Element Using Analytical Bending and Shear Rotation Interdependent Shape Functions", International Journal for Computational Methods in Engineering Science and Mechanics, Vol. 7, pp. $425-431$

[9] Javidinejad, A. (2012): "Buckling of Beams and Columns under Combined Axial and Horizontal Loading with Various Axial Loading Application Locations", Journal of Theoretical and Applied Mechanics, Vol. 42, Issue. 4, pp. 19-30.

[10] Rahai, A.R. and Kazemi, S. (2006): "Buckling Analysis of Non-Prismatic Columns Based on Modified Vibration Modes", Communications in Nonlinear Science and Numerical Simulation, Vol. 13, pp. 1721-1735.

[11] Reddy, J.N. (2006):“An Introduction to the Finite Element Method", $3^{\text {rd }}$ edition, McGraw-Hill, New York.

[12] Nickel, R and Secor, G. (1972): "Convergence of Consistently Derived Timoshenko Beam Finite Elements", International Journal. of Numerical Methods in Engineering, Vol.5, pp. 243-253. 